\title{
Inmigración, federalismo y reglamentación local en Estados Unidos
}

\author{
Laurie Reynolds \\ Catedrática de Derecho, University of Illinois College of Law, USA \\ lareynol@illinois. edu \\ Recibido: 14 de junio de 2012 \\ Aceptado: I 8 de julio de 2012
}

\begin{abstract}
Resumen
En las últimas décadas, muchos gobiernos locales, la mayoría de ciudades y pueblos han entrado en el debate nacional sobre la inmigración. Como era de esperar, la actitud que se ve al nivel local refleja el debate nacional, con una gran variedad entre una política muy favorable para la incorporación de los inmigrantes y por otro lado, una política con mucho antagonismo hacia ellos. Con el aumento de interés en cuanto a las leyes locales, se añade otro nivel de política a la inmigración. Ahora no solamente hay que entender los poderes, mandatos y leyes de los gobiernos estatales y federal, sino también las leyes, poderes, mandatos y prohibiciones de los gobiernos locales. Tanto puede ser una ciudad o pueblo como un country (condado/ municipio) donde se ve legislación que se dirige a los inmigrantes o refleja una política hacia ellos. En este artículo analizo el estatus legal de los gobiernos municipales en cuanto al tema de la inmigración y en cuanto a la relación legal que tienen los gobiernos municipales con su estado y con el gobierno federal.
\end{abstract}

Palabras clave

Inmigración, regulación local, gobierno local, federalismo.

\section{Immigration Federalism and Local Regulation in the United States}

\begin{abstract}
In recent decades, many local governments (mostly cities and towns) have entered the national debate on immigration. As was to be expected, the local governments' stance vis a vis immigrants and immigration reflects the national debate. Local policies and legislation ranges from those that are friendly to immigrants, trying to facilitate their integration into the larger society, to those that are overtly hostile to the newly arrived. As local government legislative activity increases, another level of politics and political structure is layered onto the immigration debate. In addition to the well-established state and federal interest, regulation, and mandates involving immigration, local laws now come into play as well. At the local level, both city and county governments have begun to adopt legislation targeting immigrants. In this article, I analyze the legal status of these local actions and evaluate the legal relationship between and among local, state, and federal government that informs the legality of these local initiatives.
\end{abstract}

Key words

Immigration, local regulation, local government, federalism. 


\section{INTRODUCCIÓN}

En la última década, las Administraciones locales se han ido convirtiendo en un lugar donde se suscitan debates políticos sobre los inmigrantes y la inmigración. Para algunas ciudades, los recién llegados han aportado vitalidad, diversidad y actividad económica. Cuando la llegada de inmigrantes se considera una fuerza positiva para el desarrollo de la comunidad, la Administración local probablemente busque modos de facilitar la integración de quienes acaban de llegar, al margen de si lo han hecho legal o ilegalmente, a EE.UU'. Por el contrario, para otros municipios, la inmigración plantea lo que se considera una amenaza a la estabilidad, la prosperidad y la seguridad. En esos lugares, es probable que la reglamentación adopte tintes decididamente contrarios a los inmigrantes, ya que las Administraciones locales tratan de utilizar sus potestades para conceder permisos y aprobar reglamentos generales que limiten la presencia de inmigrantes a quienes están allí de manera legal, así como para buscar maneras de excluir a los residentes ilegales o de hacerles la vida difícil ${ }^{2}$.

Junto con estas fuerzas "ascendentes", claramente situadas en el nivel de las bases, que se muestran a favor de regular y controlar la inmigración, el impulso a favor de una acción local también ha procedido desde "arriba". Dada su autoridad dominante e incontestada para regular la inmigración, no es de sorprender que el Gobierno federal haya adoptado algunas medidas explícitas para permitir, prohibir, fomentar o quizá incluso solicitar la participación local en las leyes de inmigración. Además, aunque no posean amplias potestades sobre la regulación de la inmigración, los 50 Estados sí cuentan con un poder policial propio sobre la salud, la seguridad y el bienestar de sus electores, así como una amplia autoridad soberana sobre sus subdivisiones políticas. Gracias a estos poderes, un Estado puede imponer mandatos o limitar la libertad local para responder a los extranjeros que en él residen.

Así, cualquier valoración de las potestades locales para regular a los inmigrantes o sus efectos sobre una comunidad concreta deben incluir un cuidadoso análisis, no solamente de la actual actitud federal de cara a la inmigración, sino también del marco jurídico adoptado por el Estado creador de la Administración local. Dado que las actitudes federales, estatales y locales en torno al enfoque adecuado sobre la regulación local de la inmigración difieren, las posibilidades de conflicto político y legal aumentan en consecuencia.

1 Los esfuerzos locales por ayudar a los indocumentados continúan pese a su precaria condición jurídica, pudiendo, por ejemplo, establecer carnés de identidad locales que acepten la policía y las empresas locales, como se ha hecho en la ciudad de New Haven, Connecticut. Más espectacular puede ser que una Administración local se niegue a participar en las campañas de las altas instancias del Gobierno para detener y deportar a los extranjeros en situación ilegal, como la Junta de supervisores del condado de Cook, que hace caso omiso de los exhortos federales, conocidos como detainers, para que se retenga a los inmigrantes no autorizados que hayan sido inscritos en la cárcel del condado de Cook.

2 Lo más corriente son las leyes locales que prohíben a los arrendadores firmar contratos de arrendamiento con individuos que no puedan confirmar su situación como inmigrante legal, o las leyes que niegan las licencias de apertura a los empleadores locales que no hayan confirmado el estatus de inmigración de sus empleados. 
Gracias a estos poderes, un Estado puede imponer mandatos o limitar la libertad local para responder a los extranjeros que en él residen. Así, cualquier valoración de las potestades locales para dictar disposiciones que afecten a los inmigrantes o sus efectos sobre una comunidad concreta deben partir de un cuidadoso análisis, no so lamente de la actual actitud federal de cara a la inmigración, sino también del marco regulatorio general establecido por el Estado creador de la Administración local. Da das las diferencias en las actitudes federales, estatales y locales en torno al enfoque adecuado sobre la regulación local de la inmigración, las posibilidades de conflicto político y legal, lógicamente, aumentan.

Este documento describe la relación entre las Administraciones federal, estatal y local, concentrándose en la forma en que la relación tripartita afecta al alcance de las potestades locales para tratar a los inmigrantes ${ }^{3}$. Existe una cierta tensión, casi palpable, por ejemplo, entre la reconocida doctrina jurídica de la concurrencia mediante la cual el Derecho federal puede desplazar la normativa estatal o local en inmigración (preemption principle), por una parte, y el principio igualmente bien establecido del Derecho constitucional federal de que el Gobierno federal no puede ordenar directamente a una unidad administrativa estatal o local que actúe. En la medida en que en el ámbito de la inmigración los principios de la primacía federal constitucional y legal se entrecruzan con otras medidas constitucionales federales de protección de la soberanía estatal, así como con un amplio abanico de regulaciones estatales y loca les de la inmigración, el ámbito legal se cubre de incertidumbre y no cesa de cambiar según los vientos políticos.

Las propuestas de reforma de las leyes federales sobre inmigración han fracasado una y otra vez en su tramitación parlamentaria. $Y$ dado que algunas comunidades se sienten abrumadas por los flujos de inmigrantes, las actuaciones normativas sub nacionales han aumentado de forma espectacular. No obstante, sería un error creer que estos esfuerzos nacen únicamente de la impaciencia con la reforma nacional de la inmigración o especular con que la actividad local se detendría simplemente si el Congreso fuese capaz de encontrar la voluntad política para adoptar una amplia re forma de las leyes de inmigración.

\section{I.LOCALISMO E INMIGRACIÓN}

\section{A. Una tradición de localismo}

De manera quizás un tanto sorprendente la Constitución federal omite mención alguna a las Administraciones locales. Entonces, en pura doctrina jurídica, los municipios y otras subdivisiones políticas de los Estados carecen de ley federal positiva o de principio alguno que defina sus parámetros, fije sus poderes o regule su categoría. En consecuencia, las Administraciones locales emanan exclusivamente del poder ple-

3 Una serie de Estados, que incluyen Arizona, Alabama, Utah, Oklahoma, Georgia, Carolina del sur e Indiana han aprobado sus propias normas. Estas leyes estatales quedan fuera del ámbito de estudio de este trabajo, salvo en los casos en que una disposición de las leyes estatales pueda afectar a la potestad de las Administraciones locales de dictar y aplicar normas dirigidas a regular la inmigración y a los inmigrantes. 
nario de los Estados. El Tribunal Supremo de EE.UU. describió esta situación a las mil maravillas cuando declaró en Hunter contra Pittsburgh que:

Las corporaciones municipales son subdivisiones políticas del Estado, creadas como agencias prácticas para ejercer aquellas potestades administrativas del Estado que les sean encomendadas... El número, la naturaleza y la duración de las potestades conferidas a estas corporaciones y el territorio sobre el que se ejercerán quedan a la absoluta discrecionalidad del Estado ${ }^{4}$.

No obstante el silencio constitucional federal y el modelo oficial de "criatura del Estado" del Derecho administrativo local, el Tribunal Supremo se ha desviado en distintas ocasiones de la retórica del caso Hunter contra Pittsburgh y ha respetado la tradición firmemente asentada de localismo y de amplias potestades administrativas locales del sistema federal de EE.UU ${ }^{5}$. Con los años, el tribunal ha resuelto numerosos casos en los que los demandantes solicitaban la intervención del tribunal federal para que pusiera remedio a las desigualdades causadas por la autonomía y la independencia de la Administración local. A pesar de los argumentos de que las Administraciones locales implicadas en estos casos debían ser situadas bajo el evidente paraguas del control estatal, en algunos casos muy sonados, el tribunal se inhibió. Más aún, a pesar de las reclamaciones planteadas en distintos casos de que la actuación local daba lugar a segregación racial en los distritos escolares de las áreas metropolitanas ${ }^{6}$, que el sistema local de impuestos sobre inmuebles era responsable de la desigualdad económica en la financiación de la educación local7, o de que la regulación local del uso del suelo excluía a los más pobres y a las minorías de las comunidades locales ${ }^{8}$, el tribunal apoyó las actuaciones de las Administraciones locales y destacó la importancia del localismo y la independencia y flexibilidad que aportaba al desarrollo político local. La opinión mayoritaria en el caso Milliken contra Bradley ilustra el respaldo del tribunal al control local reza:

Ni una sola tradición de la educación pública está más profundamente enraizada que el control local sobre el funcionamiento de los colegios;

4 Hunter contra la ciudad de Pittsburgh, 207 U.S. 161, 178 (1907). Esta afirmación fue matizada posteriormente en el importante caso del Tribunal Supremo Gomillion contra Lightfoot, 364 U.S. 339 (1960), en que el tribunal recalcó que el control estatal plenario sobre las Administraciones locales no inmuniza las leyes estatales contra la vigilancia constitucional federal cuando esta última ejerza este poder plenario. En el caso Gomillion, el tribunal invalidó la decisión legislativa de Alabama de retrazar los límites de la ciudad de Tuskegee para eliminar a casi todos los votantes afroamericanos del territorio de la ciudad porque lo consideró una infracción de la Constitución federal.

5 Para el análisis jurídico por excelencia de la diferencia entre falta de poder local doctrinal jurídico formal y poder local real, véase Richard Briffault, Our Localism: Part I The Structure of Local Government Law, 90 Colum. L. Rev. 1 (1990) y Richard Briffault, Our Localism: Part II Localism and Legal Theory, 90 Co lum. L. Rev. 346 (1990).

6 Milliken contra Bradley, 418 U.S. 717 (1974).

7 Distrito escolar independiente de San Antonio contra Rodríguez, 411 U.S. 1 (1973).

8 Pueblo de Arlington Heights contra Metropolitan Development Corporation, 429 U.S. 252 (1977). 
la autonomía local se ha considerado esencial tanto para el mantenimiento del interés comunitario como para el apoyo a la escuela pública y la calidad del proceso educativo ${ }^{9}$.

Por consiguiente, en el Derecho federal, aunque las Administraciones locales no dispongan de una protección o categoría constitucional expresas, el Tribunal Supremo reconoce y preserva la independencia y los amplios poderes de la actuación administrativa local. Por tanto, la jurisprudencia del alto tribunal está impregnada de un valor extraconstitucional del localismo y sus decisiones están imbuidas de deferencia, respeto y alabanza por el nivel inferior de gobierno representativo del sistema federalista de EE.UU.

\section{B. El componente de localismo de la regulación de la inmigración}

Sean cuales fueren los límites en disputa entre los poderes federal, estatal y local sobre inmigrantes e inmigración, la realidad es que los efectos de la inmigración en EE.UU. se dejan sentir ante todo y en primer lugar en el ámbito local. Las ciudades, los condados y algunos distritos especiales (como los distritos escolares y los de sanidad pública) constituyen la primera línea a la hora de gestionar los efectos de la inmigración sobre la sociedad en general. Son los primeros lugares adonde acuden los inmigrantes cuando las redes personales no pueden satisfacer sus necesidades. Dada la larga tradición localista y de iniciativa legislativa local, no es de extrañar que cualquier estudio de la participación local revele multitud de enfoques normativos y una amplia divergencia política. La regulación local de la inmigración es el corolario natural y una consecuencia de varios intereses políticos locales bien definidos, cada uno de los cuales se trata en los párrafos que siguen ${ }^{10}$.

Para empezar, las Administraciones locales suelen contar con la discreción legislativa para marcar los límites que determinarán a los electores de su comunidad. Los procedimientos legales que determinan las fronteras de la comunidad por anexión, incorporación y desanexión, por ejemplo, requieren que la comunidad decida si va a incorporar o separar tierras y a sus ocupantes. Aunque los problemas legales tiendan a girar en torno al cumplimiento de los procedimientos técnicos que generan las peticiones, audiencias, elecciones y votos, en realidad los litigios se suelen basar en argumentos más o menos declarados en que se opone el "nosotros" al "ellos" . Ésta es la misma dinámica que impregna la regulación local de los inmigrantes y la inmigración, con funcionarios electos de la comunidad llamados a adoptar decisiones fundamentales sobre la forma de incorporar a los recién llegados a la comunidad o,

9 Milliken contra Bradley, 418 U.S. 717,741-42 (1974).

10 Para un análisis excelente de este fenómeno, véase Rick Su, A Localist Reading of Immigration Regulation, 86N. CAR. L. REV. 1619 (2008).

11 Por ejemplo, considérese cómo pueden aflorar los problemas raciales en una incorporación municipal, véase In re Incorporation of the Borough of Bridgewater, 488 A. 2d 374 (Pa. Commw. 1985); y cómo las desigualdades sociales pueden subyacer a la anexión, véase In the Matter of the Enlargement and Extension of the Municipal Boundaries of the City of Jackson, Mississippi, 691 So. 2d 978 (Miss. 1997) o la desanexión, véase Ryan contra Mayor y el ayuntamiento de Demarest, 319 A. 2d 442 (N.J. 1974). 
alternativamente, sobre si intentan o no excluir a un grupo que pueda ser percibido como diferente, amenazador o costoso.

Para continuar, y especialmente en esta época de dificultades económicas, algunas de las grandes y prolongadas disputas políticas de las Administraciones locales giran en torno al modo en que se van a pagar los servicios. Fuera del contexto de la inmigración, las Administraciones locales buscan con frecuencia maneras de imponer los costes a los foráneos, como son los no residentes que puedan utilizar los servicios locales sin pagarlos. En estos casos, las ciudades pueden fijar tasas u otros mecanismos no basados en la renta o los ingresos para aliviar la carga financiera que supone prestar servicios a quienes no están sometidos al poder tributario de la Administración local. De manera similar, muchas Administraciones locales enfrentadas a grandes aumentos de la población inmigrante se ven agobiadas por la creciente demanda de servicios y los escasos ingresos para financiarlos. Según un documento de la Oficina de Presupuesto del Congreso, los ingresos fiscales aportados por los inmigrantes en general superan el coste de los servicios que reciben. Sin embargo, el superávit de ingresos se produce en el plano federal, donde muchos inmigrantes pagan impuestos sobre la renta y contribuyen a la Seguridad Social y a Medicare, prestaciones que es probable que no reciban. En cambio, en el ámbito local, donde las demandas inmediatas de servicio son mayores (especialmente en términos de educación y asistencia sanitaria), los cálculos más optimistas indican que se pide a las Administraciones locales que presten servicios que rebasan con mucho la aportación de estos mismos receptores ${ }^{12}$. Dado que la potestad tributaria de las Administraciones locales es por lo general reducida y está sometida a límites tributarios impuestos por los votantes -o la ley-, y dado que muchos de los recién llegados son pobres, éstas ven como sus recursos son totalmente exprimidos. Así, como problema puramente financiero, los inmigrantes plantean muchos desafíos idénticos a los de otros grupos (como los no residentes), cuyos miembros suponen un coste financiero para el resto de la comunidad local establecida.

Y, por último, definir el carácter de la comunidad local quizá sea la preocupación política por antonomasia y la más fundamental para las Administraciones. Estas últimas adoptan una amplia gama de ordenanzas y políticas públicas dirigidas a establecer y preservar el carácter de su comunidad mediante mecanismos reguladores como la zonificación, la regulación de subdivisiones y otras técnicas de uso del suelo. El resultado es que las unidades de la Administración local abarcan desde las comunidades densamente pobladas, diversas y multinacionales hasta los enclaves suburbanos exclusivos y homogéneos. Cada uno de ellos tiene a su disposición los mecanismos para planificar el uso del suelo que marca la pauta para toda la comunidad. En el fondo, la regulación local de su carácter depende fundamentalmente de la potestad de la Administración local para excluir: excluir usos y, consecuentemente a personas, mediante decisiones sobre los tipos de desarrollo que permitirá la comuni-

12 Oficina de Presupuesto del Congreso, The Impact of Unauthorized Immigrants on the Budgets of State and Local Governments (2007). 
dad. Los tribunales estatales dan su conformidad en general, aunque no todos, estos esfuerzos de exclusión. De hecho, el Tribunal Supremo describió esta potestad local en términos de algún modo elogiosos en un caso en que el recurrente había alegado que las leyes locales de zonificación interferían inadmisiblemente en la autonomía, la movilidad y la asociación personales. El tribunal defendió el deseo de la comunidad de de terminar su carácter e implícitamente protegió de este modo su derecho de excluir con una amplia alabanza:

Planificar la creación de un lugar silencioso con extensos jardines, poca gente y restricciones a los vehículos de motor constituyen orientaciones legítimas para guiar un proyecto de uso del suelo pensado para las necesidades familiares. Esto es una meta permisible... La potestad política no se constriñe a la eliminación de la suciedad, los malos olores y los lugares insalubres. Es lo bastante amplia como para establecer zonas donde los valores familiares y de la juventud así como el bendito aislamiento en pleno disfrute de la paz y del aire puro conviertan la zona en un santuario para las personas ${ }^{13}$.

Como declaró un importante especialista en derecho urbanístico: "Zonificación, tu nombre es exclusión"14. Y, de hecho, la aplicación de mecanismos de uso del suelo para excluir a quienes la comunidad designa extraños no deseados se remonta a los prime ros días de la zonificación y la planificación del uso del suelo en EE.UU. El impulso para la adopción de la primera ordenanza de zonificación de la ciudad de Nueva York en la primera década de 1900, por ejemplo, obedeció en gran medida a la prevalencia de sentimientos xenófobos. Considérese la siguiente descripción de los motivos por los que la ciudad de Nueva York estaba deseando adoptar su primera ordenanza de zonificación y excluir los usos no residenciales del área aledaña a la Quinta Avenida:

Los comisionados de la ciudad de Nueva York querían expulsar a la industria del vestido de la Quinta Avenida... porque los elementos que constituían la esencia de esta industria -las lenguas extrañas, el aspecto extravagante y el olor propio de sus trabajadores extranjeros...- estropeaba el ambiente en que prosperan las tiendas de lujo ${ }^{15}$.

Recapitulando, mucho de lo que hace la Administración local implica, en términos amplios, una resolución de las disputas sobre quiénes están "dentro" y "fuera”, sobre aquellos que deberían recibir servicios o no, y sobre quiénes encajan en la propia imagen que de sí misma tiene la comunidad y quiénes son vistos como una interferencia en su carácter. Las iniciativas locales para fijar o ampliar los límites territoriales,

13 Pueblo de Belle Terre contra Boraas, 416 U.S. 1, 9 (1974).

14 Donald Hagman, Taking Care of One's Own through Inclusionary Zoning: Bootstrapping Low and Moderate Income Housing by Local Government, 5 Urban Law and Policy 169 (1982).

15 Seymour L. Toll, Zoned American 158 (1969). 
para buscar formas de recuperar el coste de los servicios prestados y para definir los usos del suelo permisibles, todas ellas, implican decisiones fundamentales sobre la composición de la comunidad. El argumento aquí no es el de aplaudir los efectos excluyentes de muchas de las actuaciones normativas, sino simplemente destacar que los esfuerzos locales por regular el efecto de la inmigración en sus comunidades encaja sin problema en el ámbito de otras iniciativas legislativas locales largamente establecidas. Si se entiende desde la posición ventajosa del Derecho administrativo estatal y local, la regulación local de los inmigrantes es un ejemplo corriente del antiguo e incontestado interés de las Administraciones locales por proteger y promover los valores de la comunidad.

\section{LA ASIGNACIÓN DE POTESTADES SOBRE INMIGRACIÓN EN EL SISTEMA FEDERAL DE EE.UU.}

\section{A. Potestad federal}

\section{Exclusividad federal}

Aunque la regulación subnacional haya coexistido de hecho con las leyes federales sobre inmigración desde los primeros días de la actuación federal' ${ }^{16}$, la máxima legal predominante y generalmente incontestada había sido que la inmigración pertenece al dominio exclusivo de la Administración nacional. Este amplio pronunciamiento surge tanto de la jurisprudencia del Tribunal Supremo ${ }^{17}$, como del lenguaje explícito de la Constitución de EE.UU ${ }^{18}$. Sin embargo, ha sido tema de renovado interés y de debates doctrinales, con algunos que apoyan el reconocimiento del importante papel estatal y local en la regulación de la inmigración ${ }^{19} .{ }^{19}$ Decir que la regulación federal de la inmigración es exclusiva quizá sea, en palabras de Cristina Rodríguez, una "mentira"2o. O quizá la actual realidad de potestades compartidas, ampliamente conocida como el fenómeno del federalismo de la inmigración ${ }^{21}$, se entiende mejor como un reflejo del hecho de que la mayoría de la regulación subnacional en realidad no logra ajustarse a la definición de "regulación de la inmigración" y no queda así sujeta al ámbito de la exclusividad federal. En todo caso, tanto si el mejor punto de vista

16 Véanse, p.ej., el caso del Alcalde de la ciudad de Nueva York contra Miln, 36 U.S. 102 (1837) (que refrenda la ley de Nueva York que regulaba a los inmigrantes que llegaban al puerto de Nueva New York); y el caso Patsone contra Pennsylvania, 232 U.S. 138 (1914) (que refrenda la ley estatal que prohibía la caza a los foráneos).

17 Hay que reconocer que el Tribunal Supremo ha suscrito la exclusividad federal en materia de inmigración; véanse, p.ej., el caso Galvan contra Press, 347 U.S. 522, 531 (1954); Takahashi contra la Comisión de pesca y caza, 344 U.S. 410, 419 (1948); y el caso Hines contra Davidowitz, 312 U.S. 52, 66 (1941).

18 Véase Const. de EE.UU. Art. I, §8, Cl. 4, que permite al Congreso “Establecer una regla uniforme de naturalización."

19 Para argumentos especialmente persuasivos, véase Rick Su, A Localist Reading of Local Immigration Regulations, 86 N.C. L. Rev. 1619 (2008); Cristina M. Rodriguez, The Significance of the Local in Immigration Regulation, 106 Mich. L. Rev. 567 (2008).

20 Véase Rodríguez, supra nota 18, en 574.

21 El término se acuñó en Peter J. Spiro, Learning to Live with Immigration Federalism, 29 Conn. L. Rev. 1627 (1997). 
es que se ha rechazado la exclusividad federal o es que el propio ámbito de exclusividad nunca había sido tan amplio como para anular toda regulación subnacional, las potestades de la Administración local son normalmente lo bastante amplias como para incluir la adopción de legislación y la aplicación de algunos controles reguladores que se concentren en el estatus de la inmigración de las personas dentro de las fronteras de la Administración local.

El dictamen del Tribunal Supremo en el caso DeCanas contra Bica ${ }^{22}$ es esencial para comprender el ámbito del poder plenario federal en materia de inmigración. Aunque el tribunal en aquel caso describió la potestad federal en materia de inmigración como "incuestionablemente exclusiva,"”23 añadió el importante matiz siguiente: "el Tribunal nunca ha sostenido que toda ley estatal que de algún modo afecte a los extranjeros constituya una regulación de la inmigración y, en consecuencia resulte desplazada por esta potestad constitucional.”24 Concretamente, el tribunal ofreció la siguiente definición sobre lo que entiende que constituye una "regulación de la inmigración": "la determinación de quién puede o no ser admitido en el país, así como de las condiciones de residencia de quienes entre legalmente" ${ }^{25}$. Mientras la normativa subnacional se abstenga de entrar en estos dos ámbitos prohibidos por la definición según DeCanas de lo que constituye "regulación de la inmigración", la ley subnacional será válida y la investigación judicial a este respecto no deberá continuar. Al contrario que el análisis de prevalencia descrito en el siguiente apartado, es irrelevante la presencia o ausencia de legislación federal para el caso DeCanas. Simplemente, toda regulación o ley estatal o local que constituya una "regulación de la inmigración" rebasa el ámbito de la potestad de la Administración porque ha invadido sin permiso un ámbito federal exclusivo.

Mientras las leyes locales se mantengan alejadas de la prohibición de DeCanas, no serán invalidadas por una invasión no permitida de la potestad del Gobierno federal. En este sentido, merece la pena señalar que la ley de California debatida en el caso DeCanas porque prohibía emplear a sabiendas a un inmigrante ilegal, fue declarada conforme a la Constitución y por consiguiente no invasiva de la exclusividad federal en materia de regulación de la inmigración ${ }^{26}$. Así, tanto el lenguaje de la sentencia como la ley estatal sobre la que recayó rebaten claramente el argumento de que la ley federal establece un área expansiva de prerrogativas reguladoras más allá del ámbito de las iniciativas de las Administraciones estatal y local.

22424 U.S. $351(1976)$.

23 Id. en 354.

24 Id. en 355.

25 Id.

26 Con posterioridad al dictamen del caso DeCanas, el Congreso priorizó expresamente la potestad estatal confirmada por el tribunal en una ley federal. Véase 8 U.S.C. §1324(a)(h)(2) (que prohíbe que "cualquier ley estatal o local imponga sanciones civiles o penales... a quienes empleen... extranjeros en situación ilegal”). 


\section{Poderes federales prevalentes}

Con todo y con ello, aunque se pueda limitar el núcleo de la exclusividad federal para legislar sobre inmigración, el Estado federal tiene en la práctica poderes ilimitados, no solo para legislar directamente, sino también para determinar el contorno admisible de los poderes estatal y local en este terreno. Tal potestad para dirigir, prohibir o fomentar leyes estatales y locales surge de la interacción entre la concesión de poder específica y tasada de la Constitución en materia de inmigración al Gobierno federal y la fuerza de la Cláusula de supremacía de la Constitución ${ }^{27}$, según la cual las acciones federales desplazarán, invalidarán o prevendrán aquellos esfuerzos estatales y locales contrarios a la misma siempre que el Gobierno federal actúe en el ámbito de una de sus competencias tasadas (enumerated powers). Y cuando se trata de inmigración, ese poder federal tasado es extremadamente amplio. De hecho, el Tribunal Supremo jamás ha invalidado una ley federal de inmigración por exceder el Congreso la esfera de sus competencias. Más allá de las decisiones del Tribunal Supremo que garantizan los derechos procesales de los inmigrantes que se enfrenten a condenas penales o a la deportación, el Congreso y el Ejecutivo han recibido "virtualmente carta blanca en materia de inmigración." ${ }^{28}$

La primacía federal (preemption) sobre las leyes estatales y locales conforme a la Cláusula de supremacía no requiere del tribunal el convencimiento sobre la exclusividad federal, sino más bien identificar la intención (ya sea expresa o implícita) del Legislador federal de desautorizar una regulación de esa cuestión en el ámbito estatal y/o local. El punto de partida del análisis de primacía es, entonces, la presunción no declarada de que la ley subnacional pudiendo ser válida puede materialmente entrar en conflicto con la legislación federal. Esto quiere decir que cuando las leyes federales y la intención subyacente del Congreso cambian, también cambia el ámbito admitido para que intervengan la regulación estatal y local. En todo momento, el ámbito de actuación resultante para los poderes locales en materia de inmigración dependerá fundamentalmente del marco legal y normativo federal. Así, a medida que cambian las actitudes federales sobre inmigración, también lo hace el ámbito de los poderes estatal y local.

La doctrina de la primacía está llena de matices como resultado de una larga historia de sentencias del Tribunal Supremo, pero sus fundamentos son muy claros. Las leyes federales pueden prevalecer sobre las nacionales tanto de manera expresa (según articula una norma federal del Congreso) o tácita, mediante la interpretación y el análisis judiciales de las leyes federales y no federales competentes.

Cuando se trate de leyes federales que impliquen áreas reguladas tradicionalmente por los Estados, el Tribunal Supremo ha adoptado una "presunción de no prevalencia," ${ }^{29}$ que refleja la seriedad con la que se toma el tribunal la soberanía es-

27 Const. de EE.UU. Art. 6, Cl. 2 dispone que "[la] Constitución y las leyes de Estados Unidos... serán la ley suprema del territorio."

28 Véase Spiro, supra nota 20, en 1630.

29 Véase el caso Medtronic, Inc.contra Lohr, 518 U.S. 470, 485 (1996) ("[Nosotros] arrancamos con la suposición de que los poderes policiales históricos de los Estados no iban a ser anulados por el derecho 
tatal. Aunque la potestad del Congreso para invalidar leyes subnacionales que traten la inmigración parezca casi ilimitada, el tribunal expresó actitudes similares contra la prevalencia en su jurisprudencia sobre la ley de inmigración de $2011^{30}$.

\section{a) Prevalencia expresa}

Como sugiere su nombre, la prevalencia expresa implica una declaración explícita por parte del Congreso en el sentido de negar la potestad estatal o local para actuar en un contexto concreto. En el caso de las leyes de inmigración, el ejemplo rele vante más reciente de prevalencia expresa es el Artículo 1324a(h)(2) de la Ley de reforma y control de la inmigración, que prohíbe la imposición estatal de "sanciones civiles o penales" a aquellos que empleen a inmigrantes en situación ilegal exceptuando los "permisos y leyes similares." ${ }_{11}$ Aunque el alcance de la excepción de los permisos no sea inmediatamente aparente a primera vista y formara la base de un dictamen del Tribunal Supremo sobre el caso Cámara de comercio contra Whiting ${ }^{32}, 32$ lo que está claro es que el Congreso deseaba suprimir la potestad general sancionadora civil y penal de los Estados. En el caso de una disposición federal con una prevalencia expresa, no hay margen para discusiones o debates jurídicos. La autoridad constitucional expansiva del Gobierno nacional sobre la inmigración otorga un poder prácticamente ilimitado de prevalencia expresa.

\section{b) Prevalencia implícita}

Aunque la prevalencia expresa sea el tipo más claro y sencillo de prevalencia, la doctrina de la prevalencia también incluye dos pruebas creadas judicialmente para deducir la prevalencia aun cuando la ley federal no haya articulado expresamente una intención prevalente. Las pruebas son similares en tanto que ambas se esfuerzan por determinar la voluntad implícita del Congreso en relación con una regulación estatal o local concreta, aunque recurran a 'test' ligeramente distintos ${ }^{33}$.

Mediante el test de la prevalencia implícita consistente en el análisis del grado de “ocupación del ámbito regulado" (occupation of the field), un tribunal invalidará

federal salvo que hubiese un propósito claro y manifiesto del Congreso.”) Tal suposición contra la prevalencia quedó recientemente reafirmada en el caso Wyeth contra Levine, 129 S. Ct. 1187, 1194-95 (2009).

30 Aunque ningún caso del Tribunal Supremo haya aplicado expresamente la presunción de no prevalencia en el contexto de la inmigración, que probablemente haya que reconocer que cae en el ámbito de las áreas tradicionalmente reguladas por los Estados, el tribunal ha instado a los juzgados a que sean cautos a la hora de suponer la prevalencia del Derecho subnacional sobre inmigración cuando el Congreso no se haya pronunciado. Véase el caso Cámara de Comercio contra Whiting, 131 S.Ct. 1968, 1985 (2011). Sin embargo, un juzgado federal ha aplicado expresamente la presunción de no prevalencia en un recurso contra la ley del Estado de Arizona que regula a los inmigrantes. Véase el caso EE.UU. contra Arizona, 641 F.3d 339, 345 (9th Cir. 2011).

318 U.S.C. $\S 1324 a(h)(2)$.

32 S Ct. 1968 (2011). En este caso, el Tribunal mantuvo una ley de Arizona que condicionaba las licencias para hacer negocios en el Estado a que el empleador hubiese comprobado el estatus legal de inmigración de todos sus empleados.

33 Para un amplio estudio y análisis en español de la doctrina de la prevalencia en Derecho de inmigración de EE.UU., véase Francisco Velasco Caballero, Un Ejemplo de Funcionamiento de la "Preemption" Norteamericana: La Regulación de la Inmigración, REAF núm. 13, abril 2011, págs. 11-50. 
una ley estatal o local si concluye que las actuaciones del Congreso son tan amplias que no dejan espacio a la participación legislativa de ningún otro nivel del Gobierno. En su análisis, el tribunal se centrará en la amplitud del programa de aplicación de la norma y en la globalidad de la legislación con el fin de decidir si el Congreso deseaba permitir una regulación estatal o local complementaria o suplementaria. En el caso Cámara de Comercio de EE.UU. contra Whiting ${ }^{34}$, por ejemplo, el Tribunal Supremo se negó a reconocer que la Ley federal de reforma y control de la inmigración pretendía ocupar el campo de la regulación del estatus de inmigración del empleado. La clave para que el tribunal determinase la prevalencia mediante este 'test' fueron sus conclusiones de que: (1) la ley federal preservaba expresamente cierta autoridad estatal sobre los permisos (dificultando de este modo que se sostenga que implícitamente no queda sitio para la regulación estatal concurrente); (2) la ley estatal no alteraba el equilibrio federal entre la carga a los empleadores y la preservación de la intimidad de empleado, ya que la ley estatal seguía de manera explícita los criterios federales; y finalmente (3) que el empleo era un área tradicionalmente sujeta a la competencia del Estado. Esta investigación fundada en tres criterios ofrece un modelo de evaluación de la regulación local de la inmigración. El dictamen posterior del Tribunal en el caso Arizona contra Estados Unidos ${ }^{35}$, sin embargo, aplicó la misma doctrina de la prevalencia de ocupación del ámbito de regulación para invalidar una norma de Arizona que consideraba como infracción de una ley federal de inmigración (que exigía el registro por parte de los inmigrantes) una infracción de la ley estatal. Aunque los delitos estatales y federales penalicen con frecuencia la misma conducta, el Tribunal concluyó que la ley estatal se entrometía de manera inaceptable en "un área que el Gobierno federal se ha reservado para sí,36" concretamente, la inscripción de extranjeros. Si se da un paso más, parece obvio que la prevalencia de campo continúa siendo un recurso viable para aquellas leyes subnacionales que traten aspectos de la inmigración que hayan sido regulados por el Congreso.

La doctrina de la "prevalencia en caso de conflicto" también abre la puerta a una flexibilidad y discreción judicial amplias para invalidar las leyes estatales y locales. En el fondo, la prevalencia en caso de conflicto es una herramienta judicial que invalida una ley subnacional cuya aplicación interferiría sustancialmente en la aplicación de una norma federal ${ }^{37}$. Una vez más, el dictamen del caso Whiting ofrece un buen ejemplo sobre cómo este tipo de prevalencia se interpretará en la ley de inmigración. En este caso, una mayoría del Tribunal Supremo se negó a ver un conflicto entre la ley federal de inmigración y la de un Estado que exija a los empleadores que comprueben el estatus de inmigración de sus empleados, aun cuando pueda decirse que la

34 131 S. Ct. 1968 (2011).

35132 S. Ct. 2492 (2012).

36 Ídem en 2502.

37 Algunos tribunales definen dos versiones ligeramente distintas de prevalencia de conflicto: imposibilidad (las partes no pueden cumplir ambas leyes) y obstáculo (la aplicación de la ley subnacional crearía un obstáculo para la plena aplicación de la ley federal). Véase el caso EE.UU. contra Arizona, 641 F.3d 339 (9th Cir. 2011) (el tribunal aplica ambas doctrinas de obstáculo y prevalencia de imposibilidad a la ley de inmigración estatal). 
ley estatal sometía a los empleadores de Arizona a mayores restricciones y responsabilidades frente a los inmigrantes que la ley federal. La clave para la conclusión de "no conflicto" fue el argumento del tribunal de que los procedimientos y las consecuencias de la ley estatal eran fundamentalmente idénticos a los requisitos de la ley federal ${ }^{38}$. Por tanto, se consideró que la ley de Arizona era complementaria y estaba en armonía con la ley federal, con lo que escapó a la invalidación según la doctrina de la prevalencia en caso de conflicto. En el caso Arizona contra Estados Unidos, el Tribunal llevó un poco más allá la doctrina del conflicto, al hallar un conflicto entre el hecho de que el Congreso no penalizase a los empleados por trabajar infringiendo las leyes de inmigración y la imposición de una multa por el Estado de Arizona por esa misma conducta39.

Aunque las dos últimas decisiones del Tribunal Supremo que tratan la prevalen cia implícita en el marco de la inmigración son sin duda doctrinalmente coherentes, hacen hincapié de forma ligeramente distinta en la importancia de la soberanía estatal y la presunción de no prevalencia de la ley estatal. De hecho, mientras que en el caso Cámara de Comercio contra Whiting, el Tribunal destacó que la prevalencia implícita impone un "umbral elevado" sobre el análisis judicial y que es inadecuada una "pesquisa judicial alocada", no se hacía mención a estos principios en el caso Arizona contra Estados Unidos ${ }^{40}$, centrándose en cambio en la primacía de la potestad federal en materia de inmigración. Como muestran estos dos casos, las determinaciones subjetivas que implica la aplicación judicial de las doctrinas de la prevalencia de campo y en caso de conflicto abren un extenso espacio para la preferencia judicial por las inclinaciones políticas. Que una ley local de arrendamientos entre o no en conflicto con la ley federal de inmigración o invada el área destinada a esa ley federal de inmigración, por ejemplo, inevitablemente dependerá, al menos en cierta medida, de la simpatía del tribunal por el esfuerzo local por regular la cuestión así como de su valoración sobre la ley federal ofrecida como norma prevalente. La inevitabilidad de la subjetividad judicial no quiere decir, sin embargo, que la prevalencia implícita carezca de normas o principios. Bajo de los test judiciales enunciados subyacen otras doctrinas que inspiran la incursión judicial en la prevalencia implícita. En concreto, la importancia de la

38 Tanto las leyes estatales como las federales en este caso se fundamentaron en el sistema federal E-Verify. En pocas palabras, E-Verify es un sistema basado en Internet que permite a los empleadores confirmar el estatus de inmigración de sus empleados a efectos de cumplir las leyes federales (es un delito federal que un empleador contrate a sabiendas a un inmigrante en situación ilegal; el cumplimiento de $\mathrm{E}$ Verify garantiza que el empleador acatará la restricción). La principal diferencia entre las normas federales y estatales, al menos a efectos de prevalencia en caso de conflicto, era la forma en que se utilizaba E-Verify. La ley de Arizona obligaba a los empleadores a utilizar el E-Verify, mientras que la federal lo consideraba optativo. Véase el caso Whiting, 131 S.Ct. at 1976. El tribunal estimó que la diferencia no tenía importancia para el análisis de la prevalencia, aunque Justice Breyer sostuvo por el contrario que la ley de Arizona debería ser invalidada porque imponía cargas adicionales a los empleadores, más allá de las impuestas por la cuidadosamente equilibrada ley federal. Véase id. en 1992 (Breyer, J., disintiendo).

39 El Tribunal concluyó que: "El Congreso ha escogido deliberadamente no imponer multas pena les a los extranjeros que busquen o acepten un empleo no autorizado.” Arizona contra Estados Unidos, 132 S. Ct. en 2504. Véase también íd. En 2496.

40 Cámara de Comercio contra Whiting, 131 S. Ct. 1968, 1985. 
inherente soberanía estatal, y el hecho fundamental de que el Gobierno federal sea una Administración con poderes tasados en lugar de inherentes, como sí es el caso de los poderes estatales, debería mitigar que los jueces se precipiten hacia la prevalencia. Como es natural, esto no equivale a decir que toda regulación estatal o local de asuntos relacionados con los inmigrantes o a la inmigración debería ser inmune a u cuestionamiento ante los tribunales, sino solamente que los tribunales deberían enfocar los problemas de prevalencia implícita con cautela.

\section{B. Soberanía estatal}

Aunque muchos de los actuales litigios legales sobre la regulación local de la inmigración no impliquen al fundador de la Administración local, esto es, al Estado sobre el que se asienta el Gobierno local, el estatus del Estado como soberano autónomo con poder político inherente puede ser relevante para abordar dos tipos de cuestionamientos jurídicos relacionados con la potestad de la Administración local en materia de inmigración. En concreto, la soberanía estatal puede ser importante para un litigio sobre el alcance de la autoridad local según la ley estatal, no la federal, porque los Estados tienen plena discreción para determinar lo que las Ad ministraciones locales pueden o no hacer en prácticamente todas las áreas legales o políticas. En segundo lugar, la ley y la soberanía estatales pueden ser de relevancia si existe un debate sobre la potestad federal para requerir la participación local en los esfuerzos federales relacionados con la inmigración, en concreto en aquellos casos en que el Estado ponga objeciones a la colaboración federal-local. Esto quiere decir que la soberanía estatal puede actuar como una espada frente a su Administración local (en cuyo caso el Estado puede prohibir, solicitar o poner en marcha la actuación local) y como un escudo frente al Gobierno federal (en cuyo caso la soberanía estatal puede impedir la capacitación federal a la Administración local contra los deseos del Estado). Este apartado estudia por separado cada aspecto de la soberanía estatal.

\section{Soberanía estatal como escudo frente al poder federal}

Siempre que el Gobierno federal trate de exigir a las Administraciones inferiores que participen en un programa nacional o que apliquen cualquier parte de un programa normativo federal, saltan al estrado las preguntas y argumentos sobre la soberanía estatal. En algunos casos relevantes del Tribunal Supremo que estudian la relación estatal federal, el tribunal ha invalidado directrices legislativas federales explícitas cuyo fin era exigir la actuación estatal o local. En un caso, el Congreso había ordenado a los Estados que se hiciesen cargo de los desechos radiactivos generados dentro de sus fronteras ${ }^{41}$; en otro, el Congreso había exigido a los agentes de policía de la Administración local que comprobasen los antecedentes de los posibles compradores de armas $^{42}$. Al invalidar ambas leyes federales como una violación inadmisible de la autonomía estatal y de la reserva constitucional del poder no delegado en los Estados ${ }^{43}$, la

41 Véase el caso Nueva York contra Estados Unidos, 505 U.S. 144 (1992).

42 Véase el caso Printz contra Estados Unidos, 521 U.S. 898 (1997).

43 "Los poderes no delegados en los Estados Unidos por la Constitución, ni prohibidos por ella a los Estados, quedan reservados respectivamente a los Estados o al pueblo." Const. de EE.UU. enmienda X. 
retórica del tribunal prestó oídos a la visión de soberanía doble del federalismo: "Los Estados no son meras subdivisiones políticas de los Estados Unidos. Las Administraciones estatales no son oficinas regionales ni agencias administrativas del Gobierno federal... La Constitución, en vez de eso, 'deja a los diversos Estados una soberanía residual e inviolable...' ${ }^{44} \mathrm{Y}$ su prohibición terminante de los mandatos federales era clara: "El Gobierno federal no puede obligar a los Estados a que apliquen o administren un programa normativo federal". ${ }^{45}$

Los paralelismos entre estos casos y las políticas federales de inmigración son grandes. Si, por ejemplo, el Congreso no puede exigir a los agentes de policía local que comprueben los antecedentes conforme a una norma federal de control de las armas, resulta difícil articular argumentos legales que permitan al Gobierno federal obligar a esos mismos agentes a aplicar la ley federal de inmigración ${ }^{46}$. Como es natural, el Congreso puede anular las leyes estatales y locales cuando considere que interfieren en el programa normativo federal en inmigración. De manera similar, goza de una gran libertad para condicionar el desembolso de fondos federales a las Administraciones estatales y locales a su participación en programas federales ${ }^{47}$. Lo que parece igualmente bien establecido, empero, es que el Congreso no puede ordenar expresamente que se aplique estatal o localmente una ley o programa normativo federal.

Aplicar estos principios fundamentales del federalismo al debate sobre los actuales esfuerzos del Gobierno federal para ordenar la participación local en la puesta en práctica de sus programas políticos sobre inmigración se suscitan cuestiones legales interesantes. No es en absoluto evidente que el Congreso o el Ejecutivo federal puedan exigir a las Administraciones locales remitan las huellas dactilares de los individuos detenidos y registrados en las cárceles locales a efectos de determinar su situación migratoria. Estos mismos principios legales tampoco apoyan el argumento de que las autoridades locales deben respetar la solicitud del Gobierno federal de que detengan -en cárceles locales con cargo a su bolsillo- a los individuos cuyas huellas dactilares hayan sido transmitidas y cuyo estatus de inmigración parezca ilegal, despertando así el interés federal por detener al mismo individuo ${ }^{48}$.

44 Nueva York contra Estados Unidos, 505 U.S. en 188.

45 Id.

46 Al condicionar la recepción de fondos federales al cumplimiento estatal o local de las normas reguladoras federales, el Gobierno federal puede delimitar la política subnacional sin suscitar directamente un debate sobre la protección de la soberanía estatal ante los mandatos federales. Véase el caso Dakota del sur contra Dole, 483 U.S. 203 (1987), en que el Tribunal Supremo refrendó el uso del Congreso de la potestad de gasto para condicionar el reparto de fondos federales para autopistas entre aquellos Estados que aumentasen hasta los 21 años la edad legal para beber alcohol.

47 Al condicionar la recepción de fondos federales al cumplimiento estatal o local de las normas reguladoras federales, el Gobierno federal puede delimitar la política subnacional sin suscitar directamente un debate sobre la protección de la soberanía estatal ante los mandatos federales. Véase el caso Dakota del sur contra Dole, 483 U.S. 203 (1987), en que el Tribunal Supremo refrendó el uso del Congreso de la potestad de gasto para condicionar el reparto de fondos federales para autopistas entre aquellos Estados que aumentasen hasta los 21 años la edad legal para beber alcohol.

48 Estos hechos describen, en términos generales, el programa Secure Communities del Gobierno federal, sobre el que se ahonda en el texto anejo a las notas 56-63, infra. 


\section{Soberanía estatal como espada frente a la regulación local}

Como cuestión de doctrina jurídica, de leyes y de disposiciones constitucionales estatales, los 50 Estados tienen una potestad prevalente expansiva sobre las Administraciones locales que han creado. Pese a que el Gobierno federal puede prevalecer libremente sobre la participación estatal y local en materia de inmigración, la preva lencia estatal sobre casi cualquier norma local se puede lograr mediante las mismas doctrinas de prevalencia expresa o tácita anteriormente descritas ${ }^{49}$. Por ejemplo, un Estado se puede imponer fácilmente sobre una ordenanza de arrendamiento o de permisos a empleadores que por exigencia federal requiera comprobar el estatus de inmigración, aun cuando estas normas locales se puedan sostener a efectos de la ley federal. Desde el punto de vista estatal, no existen barreras jurídicas ${ }^{50} 50$ para que deci siones estatales puedan impedir la regulación local de la inmigración ni para exigir a las Administraciones locales que participen en los programas normativos federales sobre inmigración. De hecho, en diversos casos en los que se discutía la validez de las normas locales que incluían el estatuto de extranjería como parte de una regulación local de la actividad empresarial y del control de las relaciones propietariosarrendatarios a los tribunales acertaron al preguntar si las leyes locales recurridas habían sido anuladas por el Estado51.

\section{Posible conflicto federal-estatal-local}

Vista la relación tripartita entre las Administraciones federal, estatal y local, resulta fácil imaginar que las actitudes políticas encontradas sobre inmigración podrían generar un conflicto legal. Dicho de una forma algo simplista, si el Estado se ve en una postura opuesta a una política federal concreta, mientras que una de sus Administraciones locales se alinea con ella e intenta aplicarla, se produce una división entre, por un lado, las Administraciones federal y local y, por el otro, la estatal. Aunque este tipo de conflicto federal-estatal-local es relativamente raro en la jurisprudencia, la regulación de la inmigración ofrece los ingredientes adecuados para que surja ${ }^{52}$.

Tómense, por ejemplo, los programas del Gobierno federal Secure Communities o E-Verify. Ambos animan a las Administraciones locales a que colaboren con las regu-

49 Véase el debate en el texto anejo a las notas 30-35, supra. Véase también Paul Diller, Intrastate Preemption, 87 B.U. L. Rev. 1113 (2007), para una análisis excelente de la prevalencia estatal sobre las leyes locales.

50 En unas pocas circunstancias particulares, que implican un tipo concreto de sistema de gobierno interno, una Administración local puede gozar de una inmunidad limitada frente a las prohibiciones estatales. Véase en general Richard Briffault \& Laurie Reynolds, Cases and Materials on State and Local Government Law 331-332; 371-406 ( $7^{\mathrm{a}}$ ed. 2009). No obstante, cuesta imaginar una disputa que implique la regulación de la inmigración en que una ley local opuesta tenga preferencia sobre una prohibición legal estatal, al menos a falta de la implicación y las directrices del Gobierno federal.

51 Tanto en el caso Lozano contra la ciudad de Hazleton, 496 F. Supp. 2d 477, 521-29 (M.D. Pa. 2007) (que invalida la ley local a favor de la estatal) (p.70 dist. ct. op) como en el caso Gray contra la ciudad de Valley Park, 2008 WL 294294 en *18-19 (E.D. Mo. 2008) (que reconoce la validez de la ordenanza municipal conforme a la ley estatal), véase el artículo de RS en 1646; casos fotocopiados de juzgados.

52 Para la elaboración de los contextos en que surgen los conflictos federales-estatales-locales y éstos se resuelven, véase Laurie Reynolds, A Role for Local Government Law in Federal-State-Local Disputes, 43 Urb. Lawyer 977 (2011). 
laciones y las bases de datos federales ${ }^{53}$. Si un Estado pone objeciones a esa política federal y trata de prohibir a sus subdivisiones políticas que participen, lo que surge es una clara y aguda disputa federal-estatal sobre el alcance del poder local. El dilema jurídico doctrinal al que no parece que se ofrezca respuesta definitiva es si los principios de soberanía estatal permitirán a la Administración del Estado evitar la actuación local o, por el contrario, si los poderes plenarios del Gobierno federal en materia de inmigración bastarán, no solamente para imponerse sobre las leyes estatales contradictorias, sino también para permitir que las Administraciones locales actúen sin autorización estatal en desafío a los deseos del Estado.

Aunque se hayan denunciado pocos ejemplos de este tipo de disputa legal, cuando surge una, suscita en general debates seculares no resueltos sobre la distribución del poder gubernamental, los méritos de la centralización y la importancia de los intereses de la soberanía estatal para el debate federalista. Los casos que han llegado al Tribunal Supremo se han resuelto de dos formas contrapuestas. Por una parte, el tribunal puede repetir la retórica de la soberanía estatal de su dictamen de 1907 en el caso Hunter contra la ciudad de Pittsburgh ${ }^{54}$, con su famosa declaración de que "el número, la naturaleza y la duración de los poderes [locales]... reside en la absoluta discreción del Estado" 55 . Cuando adopta ese enfoque, el tribunal prioriza la restricción de la ley estatal, dejando así a la Administración local sin capacidad para ejercer sus poderes de apoyo a la meta federal ${ }^{56}$. De manera alternativa, el tribunal puede hacer caso omiso o rechazar los problemas de soberanía estatal y gobernar en nombre de la asociación local-federal, desechando los argumentos basados en la clara oposición estatal a la actuación de la Administración local, y centrarse en su lugar en la importancia del interés federal en juego ${ }^{57}$.

Por desgracia, las decisiones del Tribunal Supremo no ofrecen directrices claras sobre cuándo los juzgados deberían preferir uno de los dos análisis doctrinales por encima del otro. Además, las aguas desconocidas se tornan aún más procelosas por el hecho de que las Administraciones locales no tienen una categoría constitucional federal explícita ${ }^{58}$. Pero las posibilidades de que estalle un conflicto federal-estatal

53 Para descripciones sucintas de estos programas, v. la nota 33 supra y el texto adjunto a las notas 56-63, infra.

54207 U.S. 161 (1907).

55 Id. at 178 .

56 Véase, p.ej., el caso Nixon contra la Liga Municipal de Missouri, 541 U.S. 125 (2004)

57 Véase, p.ej., el caso Condado de Lawrence contra el Distrito escolar de Lead-Deadwood $n^{\circ} 40-1$, 469 U.S. 256, 261-64 (1985) (que identificó los intereses federales al conceder a las Administraciones locales la "libertad y flexibilidad," id. en 263 , de utilizar los ingresos federales para ocuparse del aumento de las necesidades que impone a sus jurisdicciones la presencia de tierras federales exentas de tributación); y el caso Ciudad de Tacoma contra los contribuyentes de Tacoma, 357 U.S. 320, 327 nn. 8-9 (1958), que recalcó los intereses federales en la defensa nacionales, las aguas navegables y el comercio interestatal.

58 Véase en general Briffault \& Reynolds, supra nota 45, en 68-173, para un análisis de cómo la carencia de referencias textuales ha afectado el tratamiento que el Tribunal Supremo hace de las Administraciones locales. El importante artículo de la catedrática Joan Williams fue uno de los primeros en reseñar las teorías incongruentes que subyacen en los dictámenes del tribunal. V. Joan C. Williams, The Constitutional Vulnerability of American Local Government: The Politics of City Status in American Law, 1986 Wis. L. Rev. 83. 
local en el campo de las leyes sobre inmigración son verdaderamente reales, dadas las grandes divergencias entre las Administraciones estales y locales sobre las políticas del Gobierno federal en materia de inmigración ${ }^{59}$. Su resolución judicial dependerá, entre otras cosas, de los puntos fuertes que se perciben en el interés federal, la importancia atribuida a la retórica del tribunal al defender y encomiar la soberanía estatal, así como en una valoración de la relación preexistente de la Administración local con el Estado en términos de asignación estatal-local del poder.

\section{EL ESPACIO PARA LA REGULACIÓN LOCAL DE LA INMIGRACIÓN}

Tras establecer el marco jurídico general a partir del cual se valora la regulación local de la inmigración, este apartado se centra en cómo se deberían aplicar los principios en los recursos judiciales contra ordenanzas y políticas locales. Aunque el resultado de cualquier caso particular no es bajo ningún concepto claro, se pueden establecer algunas directrices generales. En este esfuerzo, adopto una categorización de la regulación de la inmigración local creada por el profesor Rick Su ${ }^{60}$, que clasifica las leyes locales como directas, indirectas o aparentemente neutrales.

\section{A. Regulación local directa}

La regulación directa se produce cuando las Administraciones locales asumen el poder para aplicar directamente las leyes federales. En aplicación del programa cita do habitualmente como $\$ 287(\mathrm{~g})^{61}$, por ejemplo, los funcionarios federales y locales firman un Memorando de entendimiento por el que el Gobierno federal autoriza a los funcionarios de las Administraciones locales a que apliquen directamente las leyes federales sobre inmigración. En esta situación, los funcionarios locales son fundamentalmente designados como agentes del Gobierno federal y pueden detener a

59 Se pueden apreciar insinuaciones sobre los tipos de problemas que plantearían estas disputas en el caso Ciudad de Nueva York contra EE.UU., 179 F.3d 29 (2d Cir. 1999) y en el de EE.UU. contra Illinois, 2009 WL 662703 (C.D. Ill. 2009). En el primero, la ciudad de Nueva York recurrió sin éxito la legitimidad de una ley federal que anulaba un decreto ley municipal que prohibía a los funcionarios de la ciudad facilitar información al Gobierno federal sobre el estatus de inmigración de los extranjeros. Aunque el tribunal federal advirtió que el Congreso no podía ordenar a Nueva York que facilitase esa información, no halló barreras legales para la anulación por parte del Gobierno federal de la prohibición de la ciudad. La distinción entre una ley federal que obliga a las Administraciones locales a actuar (inconstitucional) y una que no permita a las Administraciones locales prohibir la transmisión voluntaria de datos (constitucional) no es a primera vista obvia. En un contexto federal-estatal-local de algún modo distinto, el Estado de Illinois aprobó una ley destinada a impedir que el sector privado utilizase el sistema E-Verify del Gobierno federal. Véase 820 ILCS $\$ 55 / 12$. Aunque se consideró que la ley quedaba anulada por las leyes federales en el caso EE.UU. contra Illinois, 2009 WL 662703 (C.D. III.), el tribunal no rebatió la prevalencia explícita de la ley estatal sobre la capacidad de la Administración local para exigir a los empleadores locales que participen en el sistema E-Verify. Véase 820 ILCS $§ 55 / 12(d)$. California ha aprobado una ley similar, que prevalece sobre el poder de la Administración local para exigir a los individuos que participen en el sistema E-Verify. Véase Ley de la Asamblea de California n 1236, 10 de octubre de 2011 (titulada la "Ley de aceleración del empleo"). No queda del todo claro cómo actuarían los principios de federalismo en el telón de fondo de esta clara disposición de prevalencia de la ley estatal.

60 Véase Rick Su, supra nota 18

61 Este programa se originó en la Ley de reforma de la inmigración ilegal y la responsabilidad de los inmigrantes de 1996, véase 8 U.S.C. $\$ 1357$. 
inmigrantes. Dada su naturaleza cooperativa, la participación se limita a Administraciones locales serviciales que compartan la actitud del Gobierno federal sobre inmigración ilegal.

Se produce una forma ligeramente más pasiva de regulación local directa cuando las Administraciones locales simplemente actúan como conducto de las agencias federales. Como consecuencia del reciente programa Secure Communities (citado a menudo como S-Comm), cuando los agentes de la policía local inscriben a un individuo en la cárcel, sus huellas dactilares no solamente se transmiten al FBI y otras agencias encargadas de aplicar la ley, sino también a los funcionarios de inmigración. En este punto, los funcionarios pueden enviar un exhorto solicitando que la Administración local lo notifique al Gobierno federal en las 48 horas previas a la liberación del individuo de la custodia local, dando así tiempo a las autoridades de inmigración para hacerse cargo de la custodia y llevar a cabo su propio arresto ${ }^{62}$.

Los resultados de estos dos programas, $\$ 287(\mathrm{~g})$ y S-Comm, son casi idénticos ${ }^{63}$ : ambos culminan con la custodia por parte de funcionarios de inmigración. Sin embargo, ambos programas conllevan niveles muy distintos de participación local. Mientras que el programa $§ 287(\mathrm{~g})$ requiere la valoración y la aplicación local independiente de las normas federales, con el S-Comm se elimina la discreción local, o al menos se aparta a un punto anterior en el proceso ${ }^{64}$, dado que la participación del funcionario local se limita a transmitir los datos al Gobierno federal.

Dado que el Gobierno federal transmite automáticamente todas las huellas dactilares enviadas por las autoridades locales al FBI al Homeland Security y a las autoridades de inmigración ${ }^{65}$, el margen para la oposición local al programa puede parecer muy limitado. Ninguna Administración local ha dejado de enviar las huellas dactilares al FBI; esta decisión sería revocada de inmediato por el Estado. Pero en la práctica, las Administraciones locales han encontrado formas creativas -y aparentemente legales- de evitar la participación. Las más directas sean quizá las ordenanzas que se niegan a cumplir los exhortos a menos y hasta que el Gobierno federal reembolse al condado el coste de las 48 horas de detención adicional ${ }^{66}$. Otro enfoque, ligeramente menos categórico, acepta cumplir algunos -no todos- los exhortos, en concreto los emitidos para determinados delincuentes $\operatorname{convictos}^{67}$. Con un enfoque ligeramente

62 El cumplimiento del exhorto es voluntario. Véase 8 C.F.R. §287.7.

63 S-Comm ha sido descrito por los oponentes como la "Versión 2.0" del programa 287(g).

64 Aunque los funcionarios locales no tengan discrecionalidad a la hora de aplicar las leyes federales sobre inmigración en virtud del S-Comm, conservan sin duda un importante control para ponerlas en marcha, es decir, la decisión inicial de si registran o no a un individuo. Las pruebas conocidas sugieren que algunos agentes de policía son más rápidos a la hora de arrestar a determinados individuos que antes de que existiese el programa S-Comm.

65 Véase Kirk Semple y Julia Preston, Deal to Share Fingerprints is Dropped, Not Program, New York Times, 6 de agosto de 2011.

66 Véase la Ordenanza del condado de Cook n 11-0-73, adoptada el 7 de septiembre de 2011, disponible en https://agenda.cookctyclerk.com/Upload/Ordinance_pdf_090711_88.pdf (pág. 8).

67 Para una copia de esta norma, adoptada por el Condado de Santa Clara, California, véase: http:// www.sccgov.org/SCC/docs\%2FSCC\%20Public\%20Portal\%2Fattachments\%2FBOS\%20 
distinto, pero reflejando la misma actitud anti S-Comm, el alcalde de Washington D.C. promulgó una orden ejecutiva ordenando a la policía que dejase de tomarles las huellas digitales a los individuos arrestados por faltas, como las de la ley de contenedores abiertos de D.C. A falta de huellas digitales, no hay información que transmitir al Gobierno federal ${ }^{68}$.

Cuando las políticas federales se filtran al ámbito local, entonces la Administración local mantiene su autoridad y puede negarse a participar, al menos mientras el Estado no exija la participación local. La Administración local también tiene la discreción para adoptar soluciones alternativas creativas, como muchas de ellas han hecho para limitar su participación en el S-Comm, asumiendo de nuevo la ausencia de la interferencia y limitación estatal. Al negarse a cumplir los exhortos federales, o al cambiar las prácticas locales de toma de huellas, la Administración local es capaz de evitar que se mezclen sus poderes para aplicar la ley local con los controles federales de la inmigración.

\section{B. Regulaciones indirectas}

La regulación indirecta de la inmigración se refiere a las normas locales que condicionan la participación en actividades reguladas localmente para que el estatus del extranjero sea conforme a la legalidad. Lo más habitual es que estas leyes regulen el arrendamiento de casas o la contratación de empleados dentro del territorio de la Administración local. Las ordenanzas funcionan normalmente incorporando normas federales sobre la presencia legal en EE.UU. y exigiendo a los empleadores o a los arrendadores que comprobaran el estatus de inmigración de los individuos a quienes contratan o alquilan una vivienda. Este tipo de regulación legal experimentó un fuer te impulso en épocas recientes, en el caso del Tribunal Supremo de la Cámara de comercio contra Whiting ${ }^{69}$, que confirmó una ley de Arizona que revoca la licencia de negocio de cualquier empleador que "a sabiendas o intencionalmente emplee a un extranjero sin papeles"70. Esta disposición, a su vez, incorpora el sistema federal E Verify, conforme al cual un empleador puede comprobar el estatus de inmigración del empleado en la base de datos federal, y así presumir que éste respeta la legislación estatal.

En contra de la alegación de los oponentes del caso Whiting de que la ley de Arizona era una regulación migratoria inadmisible, o que había quedado anulada por la ley federal, el Tribunal Supremo interpretó la exención de la Ley de reforma y con trol de la inmigración sobre la potestad estatal para otorgar licencias ${ }^{71}$ en el sentido de

Summary\%2F2011\%2FSummary101811.pdf (pág. 4) (que autoriza los exhortos para quienes hayan sido sentenciados por un delito en los últimos diez años o excarcelados en los últimos cinco).

68 Para lo detalles sobre este programa, véase Tim Craig, D.C. Won't Cooperate with Federal Immigration Enforcement, Washington Post, 19 de octubre de 2011, disponible en http://www.washingtonpost. com/local/dc-politics/dc-wont-cooperate-with-federal-immigration-enforcement-mayor-says/2011/10/19/glQAznSpyL_story.htm.

69131 S.Ct. 1968 (2011).

70 Az. Rev. Stat. §§ 23-211, 212.

71 Las leyes federales prohíben expresamente que "cualquier ley estatal o local imponga san- 
que permitía al Estado exigir a los empleadores que comprueben el estatus federal de inmigración de sus empleados como condición previa a la autorización para realizar negocios en el Estado. Aunque el caso implicaba un sistema de licencias estatal y no local a los empleadores, el Tribunal Supremo ordenó a los tribunales federales inferiores que tuviesen en cuenta la legalidad de la ordenanza Hazleton a la vista de la decisión del Tribunal72. Parece probable que la regulación local de la relación empleador-empleado, siempre que se ajuste a los límites de la norma de Arizona, también se acogerá sin demasiadas dificultades a la misma exención federal de licencia legal.

Aunque la legalidad de la regulación local de la relación empleador-empleado parezca bien establecida y sujeta a límites bastante claros, no se puede decir lo mismo de las leyes locales para arrendadores e inquilinos que incluyen el estatus legal de la inmigración como condición para arrendar una propiedad dentro de la jurisdicción. Incluso tras el segundo dictamen del Tribunal Supremo dos años después ${ }^{73}$ que trataba la regulación subnacional de la inmigración, el panorama continúa muy borroso. La incertidumbre surge de diversos hechos: la falta de autorización normativa federal específica para las regulaciones de la relación arrendador-inquilino ${ }^{74}$; la ausencia de una orientación directa del Tribunal Supremo; el amplio abanico de enfoques adoptado por las leyes que regulan la relación arrendador-inquilino; y los dictámenes divergentes de los tribunales federales inferiores que han tratado este tipo de norma local.

La mayoría de los tribunales federales inferiores ${ }^{75}$, pero no $\operatorname{todos}^{76}$, han invalidado las leyes locales sobre las relaciones arrendador-inquilino. Un estudio de estos casos, combinado con las insinuaciones que se encuentran en los dictámenes del Tribunal Supremo sobre los casos Whiting y Arizona, sugiere que probablemente su legalidad dependa de un conjunto de factores. En primer lugar, las leyes locales que investigan más de cerca las disposiciones sobre licencias confirmadas por el Tribunal en el marco del empleo son las más fáciles de defender contra los recursos por preva-

ciones civiles o penales" a los empleadores, pero exime expresamente de esa prohibición a las "leyes de concesión de licencias y similares." 8 U.S.C. §1324(a)(h)(2).

72 Véase el caso Lozano contra la ciudad de Hazleton, 131 S.Ct. 2958 (2011) (que vacía la decisión siguiente y la remite para su estudio a la vista del caso Whiting)

73 En el caso Arizona contra Estados Unidos,132 S. Ct. 2492 (2012), el Tribunal invalidó una serie de disposiciones legales estatales porque la ley federal prevalecía sobre ellas de manera implícita.

74 Este hecho distingue de manera crucial las ordenanzas sobre arrendador-inquilino de las relativas a empleador y empleado, que se estudian por el poder judicial con una autorización normative federal específica de "licencias y leyes similares." 8 U.S.C. §132a(h)(2).

75 Véase p.ej. Ios casos Lozano contra City of Hazleton, 620 F.3d 170 (3rd Cir. 2010); Keller contra Freemont -F Supp, 2d-, 2012 WL 537527 (D. Nb. 2012) (que invalidaba algunas, aunque no todas, disposiciones de una ley local sobre arrendadores e inquilinos); Villas at Parkside Partners contra City of Farmers Branch, 675F. 3d 802 (5th Cir. 2012); Garrett contra City of Escondido, 465 F.Supp. 2d 1043 (S.D. Cal. 2006).

76 Véase p.ej., el caso Gray contra la ciudad de Valley Park, Mo., 2008 WL 294294 (E.D. Mo. 2008), parcialmente confirmado, 567 F.3d 976 (8th Cir. 2009). Nótese también que el dictamen del tribunal de distrito Keller confirmó la sección del la ordenanza en la que se requería a los posibles inquilinos que facilitasen información sobre su estatus de inmigración. La ordenanza fue demasiado lejos, según el dictamen, por la forma en que imponía multas tanto al arrendador como al inquilino si este último no podía demos trar un estatus de inmigración legal. 
lencia. Convertir al arrendador, en lugar de al inquilino, en el objetivo de la regulación también elimina algunas de las objeciones más obvias a la prevalencia. También es esencial incorporar las normas federales de inmigración, en lugar de crear una nueva definición local de inmigrante legal. Por último, las leyes que evitan que se añadan multas o que se establezcan procedimientos de revisión judicial para hacer exigibles las infracciones también se basan en fundamentos jurídico-doctrinales más sólidos. Dicho en pocas palabras, aunque no exista una respuesta legal definitiva, la ordenanza local sobre arrendadores e inquilinos limitada a condicionar la capacidad continuada del arrendador de entrar en el negocio local del arrendamiento o su cumplimiento de un requisito local de comprobar el estatus federal de inmigración de todos sus inquilinos probablemente resista los recursos legales mejor que las que contengan cualquiera otra de las características antes descritas. Queda por ver si el Tribunal ofrecerá un margen de regulación cómodo para las regulaciones locales de distintos tipos o, por el contrario, si los poderes locales se interpretarán de forma estricta como si estuviesen limitados a las leyes de concesión de licencias empleador-empleado.

\section{Leyes neutrales}

La aparente neutralidad de una ordenanza local no la hace inmune al ataque de una ley federal. Si se adopta una ley con espíritu discriminatorio contra los extranjeros ${ }^{77}$, o si se aplica de una forma discriminatoria contra los individuos tomando como base su origen o su raza, quedará invalidada por la ley constitucional federal. Este argumento se presentó en el célebre caso de 1886 Yick Wo contra Hopkins ${ }^{78}$, en el cual el Tribunal Supremo derogó una ordenanza de San Francisco que regulaba la construcción y manejo de lavanderías porque solamente se aplicaba en la ciudad contra chinos en situación ilegal. El punto central aquí es que una regulación que en apariencia es neutra puede ser invalidada por un tribunal únicamente si quienes se oponen a la misma demuestran la voluntad discriminatoria de la misma o en su aplicación. En la mayoría de los casos, las cosas no son tan evidentes. Un análisis reciente de la zonificación en algunas comunidades de California, por ejemplo, sugiere que las leyes locales que prohíben la venta en garajes o el secado de la colada al aire libre estaban dirigidas en realidad contra los vecindarios latinos ${ }^{79}$. Otro artículo denuncia una redada en Long Island, Nueva York, con el fin de identificar ocupantes que infringiesen el código de vivienda, lo cual dio como resultado el desahucio de más de 100 inmigrantes latinos, la mayoría de los cuales se consideraba que residían ilegalmente en EE.UU ${ }^{80}$.

La adopción y aplicación de leyes en apariencia neutrales cuya validez se puede defender con una legítima preocupación política local como es la de preservar el carácter y la estética de la comunidad o la de prevenir el hacinamiento, probable-

77 Véase, p. ej., el caso Pueblo de Arlington Heights contra Metropolitan Housing Development Corp., 429 U.S. 252 (1977).

78 Yick Wo contra Hopkins, 118 U.S. 356, 374 (1886).

79 Véase Stacy Ann Harwood, Planning in the Face of Anti-Immigrant Sentiment, de próxima aparición en Michael Rios and Leonardo Vazquez, eds., Dialogos, Cap. 2 (2012).

80 Véase Rick Su, Local Fragmentation as Immigration Regulation, 47 Hous. L. Rev. 367, 368 (2010). 
mente se asienten sobre bases sólidas, al menos en ausencia de pruebas concretas de voluntad discriminatoria. Como es natural, una regulación aparentemente neutral puede conculcar otras garantías constitucionales como la protección de la libertad de expresión de la Primera Enmienda. Sobre esta base, se invalidó la normativa contra el día del trabajador, adoptada en Redondo Beach, California, sin necesidad de abordar la cuestión de si tenía una intencionalidad oculta contra los inmigrantes, algo por lo demás prohibido ${ }^{81}$.

La amplia potestad de las Administraciones locales para regular su entorno y para proteger la salud, la seguridad y el bienestar de sus votantes incluye sin duda el poder de regular de muchas formas lo que, dependiendo del contexto, puede suponer una actitud amigable $u$ hostil hacia los inmigrantes en la comunidad. En estos casos, es en el escenario político y legislativo, más que en un foro legal, donde probablemente se ganen o pierdan las batallas.

\section{CONCLUSIÓN}

Es probable que las Administraciones locales continúen posicionándose en cuanto a la mejor forma de responder a la presencia de inmigrantes en sus comunidades. Igual que el país está fuertemente dividido sobre el camino adecuado para reformar las leyes federales sobre inmigración, también lo están las opiniones locales en todo el espectro político. Dado que las actitudes de la Administración sobre la inmigración abarcan desde la bienvenida hasta la hostilidad abierta, es de esperar que los esfuerzos legislativos muestren la misma variedad. El campo legal para la regulación local es lo bastante amplio como para incluir una importante cantidad de flexibilidad e innovación locales, que engloben una serie de técnicas para reflejar y poner en práctica la relación de la comunidad con su población inmigrante. No importa la política subyacente a la regulación de la inmigración, la legalidad de cualquier ordenanza o política legal se verá reforzada si respeta varias directrices generales basadas en los principios jurídicos estudiados en las páginas anteriores.

En primer lugar, los funcionarios locales deberían abstenerse de actuar desafiando abiertamente a las leyes federales y mantenerse alejados de las regulaciones que se podrían considerar como invasoras del ámbito exclusivo del poder federal, es decir, "una determinación de quien debería o no ser admitido en el país, y las condiciones en que puede quedarse quien haya entrado legalmente ${ }^{82}$ ". En segundo lugar, si el esfuerzo local se dirige a limitar la capacidad de los inmigrantes ilegales de participar en el mercado local, regulando, por ejemplo, el mercado de la vivienda o a los trabajadores, los criterios empleados por la Administración local deben seguir las normas federales tan estrictamente como sea posible. Cualquier desviación sustancial de las normas federales o todo intento en nombre de la propia Administración local para tomar sus propias resoluciones sobre la legalidad de presencia de un individuo en

81 Véase el caso Comité de Jornaleros de Redondo Beach contra la ciudad de Redondo Beach, 657 F.3d 936 (9th Cir. 2011).

82 Ese lenguaje es la definición más clara disponible sobre el ámbito de la esfera federal exclusiva. Véase el caso DeCanas contra Bica, 424 U.S. 351, 355 (1976). 
este país, probablemente sean impugnados. En tercer lugar, la ordenanza local más defendible es la que permanezca cerca de la ley de concesión de licencias mantenida en el caso Whiting, y resista los embates para imponer multas o establecer nuevos procedimientos judiciales. Por último, la ordenanza local debería limitar su ámbito a los tipos de asuntos que tradicionalmente se consideran dentro de la esfera del poder policial de la Administración local. Las ordenanzas cuyos efectos puedan ir más allá del territorio de la Administración local, o cuyo fondo no se vincule estrechamente a los tradicionales problemas y objetivos locales de la regulación son objetivos claramente objeto de recursos en cuanto a su prevalencia. Dado que las ordenanzas locales varían mucho en cuanto a los detalles de su ámbito, su marco legal y las con secuencias derivadas de su aplicación, es difícil hacer generalizaciones amplias. La viabilidad jurídica de cualquier ley local concreta dependerá de la forma en que se aplique realmente a un caso particular, tanto en la manera en que afecte a la comunidad local como al modo en que interactúe con las estructuras regulatorias estatales y federales. Y como las actitudes y la legislación estatales y federales sobre inmigración cambian, también lo harán los parámetros de la regulación local admisible.

De alguna manera, otorgar flexibilidad y discrecionalidad a las Administraciones estatales y locales puede aliviar la presión para emprender acciones nacionales. Es quizá menos probable que los representantes federales de los Estados que han adoptado leyes estatales estrictas presionen a favor de una legislación similarmente punitiva en el plano nacional. En el análisis final, es probable que la valoración legal de la regulación subnacional impulse un equilibrio delicado entre, por una parte, el reconocimiento del legítimo interés local por responder a las circunstancias variadas en que se desarrollan las comunidades de inmigrantes en el país y, por otra parte, el interés superior federal de asegurar que la política de inmigración sea un sistema regulador cohesionante, que trate a los individuos con justicia y respete las libertades civiles. Las actuaciones locales son un componente importante de esa cohesión global y seguirán formando la base a partir de la cual se integren los inmigrantes en el sistema federal, con su reconocimiento de que existe un espacio para la coexistencia de la regulación federal, estatal y local, incluso en un sistema construido sobre los cimientos de unos poderes federales expansivos de carácter regulador y destinados a aplicar la ley. 